\title{
LOS CONSTRUCTORES DEL ESTADO: \\ LOS INGENIEROS ESPAÑOLES Y EL PODER PÚBLICO \\ EN EL CONTEXTO EUROPEO (1840-1900)'
}

\section{The state-builders: Spanish engineers and public power in the European context (1840-1900)}

\author{
DARINA MARTYKÁNOVÁ \\ Universidad Autónoma de Madrid \\ darina.martykanova@uam.es \\ JUAN PAN-MONTOJO \\ Universidad Autónoma de Madrid \\ juanluis.pan@uam.es
}

Cómo citar/Citation

Martykánová, D. y Pan-Montojo, J. (2020)

Los constructores del Estado: los ingenieros españoles y el poder público

en el contexto europeo (1840-1900).

Historia y Política, 43, 57-86

doi: https://doi.org/10.18042/hp.43.03

(Recepción: 06/07/2019; evaluación: 16/09/2019; aceptación: 28/12/2019; publicación: 13/05/2020)

Resumen

En España, los ingenieros constituyen uno de los ejemplos más importantes de élites profesionales. Su ascenso está estrechamente ligado al proceso de la construcción del Estado. Este artículo primero establece los rasgos principales que han caracterizado la ingeniería como campo de conocimiento y como profesión desde el

Este artículo se enmarca en el proyecto PGC2018-097023-B100 financiado por el Ministerio de Ciencia e Innovación. 
siglo XVIII. A continuación, ofrece una visión sintética de las paradojas del proceso lento y complejo de la construcción del Estado en Espańa, prestando atención al papel ambiguo que los ingenieros desempeñaron en este proceso y a los límites de su acción. Por último, el texto debate el concepto del ingenierismo, que se entiende como: a) la tendencia de juzgar la intervención pública en términos de promover las obras públicas, y b) como las aspiraciones de los ingenieros al liderazgo socioprofesional y al reconocimiento público de tal liderazgo. El ingenierismo puede entenderse como una construcción social heredera de la representación social decimonónica de una relación estrecha entre las políticas públicas, el cambio técnico y la ingeniería en tal que profesión.

\title{
Palabras clave
}

Ingenieros; profesión; obras públicas; Estado.

\begin{abstract}
Engineers represent one of the most prominent examples of professional elites in Spain. Their rise is closely linked to the state-building process. This article first outlines the main traits that have characterised engineering as a field of expertise and as a profession in Spain since the 18th century. The following section provides a synthetic vision of the paradoxes in the slow process of construction of the Spanish state, paying particular attention to the ambiguous role of engineers and to the limits of their action. Finally, it discusses the concept of ingenierismo [engineerism], which is understood both a) as an inclination to judge public (state) intervention in terms of carrying out public works; and b) as the aspirations of the engineers to socio-professional and political leadership and the public acknowledgement of such leadership. Engineerism can be seen as a cultural construct, in itself a legacy of the 19th century social representation of the existence of a close relationship among public policies, technical change and engineering as a profession.
\end{abstract}

\section{Keywords}

Engineers; profession; public works; State. 


\section{SUMARIO}

I. INTRODUCCIÓN. II. EL INGENIERO COMO MODELO DEL EMPLEADO PÚBLICO. III. LOS INGENIEROS Y LA CONSTRUCCIÓN DEL ESTADO EN ESPAÑA, 1835-1900. IV. EL ESTADO EN OBRAS: LAS TAREAS, PRÁCTICAS Y REPRESENTACIONES DE LOS INGENIEROS. V. CONCLUSIONES. BIBLIOGRAFIA.

Por todas partes se ve el incremento, la importancia que han tomado las obras públicas en España y no puede menos que seguirse continuando por esta traza abierta a procurar el engrandecimiento del país y dar ocupación a la numerosa clase obrera [...].

Dirección General de Obras Públicas, Memoria sobre el progreso de las obras públicas en España, Revista de Obras públicas, 1864, 148)².

\section{INTRODUCCIÓN}

Philip Abrams ha definido el Estado nacional como un fenómeno dual: el Estado sistema, una serie de instituciones políticas y administrativas organizadas en una estructura, que gobiernan un territorio y su población en el nombre de la nación; y el Estado idea, la representación de un ente político unido y coherente, con sus límites definidos por la ley, autónomo frente a otros poderes y legitimado por su compromiso con el bienestar de una comunidad nacional imaginada ${ }^{3}$. Esta dualidad del concepto es paralela a la tesis de Bourdieu según la que las instituciones existen dos veces: en lo objetivo y en lo subjetivo, en las cosas y en el cerebro ${ }^{4}$.

Para que el Estado gobierne efectivamente el territorio y la población que lo habita y para que el Estado proyecte las representaciones de sí mismo que permiten su consolidación y reproducción, las instituciones administrativas requieren recursos materiales, organizativos e informativos, pero también recursos simbólicos. Acumular y distribuir esos recursos constituye una de las

\footnotetext{
2 http://ropdigital.ciccp.es/pdf/publico/1864/1864_tomoII_13_01.pdf.

3 Abrams (1988).

4 Bourdieu (2012): 185.
} 
tareas principales de los agentes estatales en todo momento y, en mayor medida, en las fases iniciales de los procesos de construcción del Estado. En ese punto de partida, particularmente en los casos de rupturas intensas con los sistemas políticos anteriores como ocurrió entre la Espańa liberal y la anterior monarquía católica transatlántica, las élites político-administrativas deben combinar el desarrollo de los nuevos elementos político-simbólicos y la delimitación y definición de la sociedad y del mercado nacionales con lo que podríamos llamar acumulación primitiva de recursos: la obtención de una base informativa, patrimonial, fiscal y personal mínima para sentar los fundamentos de su propio crecimiento 5 .

En esa fase inicial de la construcción del Estado, los ingenieros, organizados en España en cuerpos estatales, igual que en Francia y Rusia, jugaron un papel clave en la identificación, inventario y suministro de un amplio abanico de recursos materiales y simbólicos. El colapso del imperio español iniciado en 1808 hizo difícil que las élites políticas de la monarquía constitucional del siglo XIX gobernasen el país mediante la readaptación de los mecanismos administrativos heredados, como ocurrió en otros Estados europeos. Tampoco pudieron hacer avanzar las reformas liberales sin una larga y tortuosa negociación con las oligarquías locales. Las élites de los pueblos conservaron el poder de promover, obstruir o paralizar la cooperación con el proyecto estatal por parte de las comunidades locales. Para sustituir el poder imperial extenso, difuso y descentralizado por un poder intenso, concreto y concentrado, hizo falta, paradójicamente, aceptar a corto plazo lo opuesto a este objetivo: un arreglo inicial casi confederal ${ }^{6}$. Esta distribución inicial de poder marcó profundamente la evolución de un Estado definido por las sucesivas constituciones a partir de 1837 como unitario y centralizado, pero que solo podía funcionar recurriendo a redes clientelares que operaban a varios niveles 7 .

España no destacó entre otros países europeos y americanos por su gobierno negociado con los poderes locales: pactos de este tipo resultaron comunes, casi diríamos que imprescindibles, en otros muchos procesos de

5 Esos pasos iniciales de reunir empleados públicos, que hagan legible el espacio geográfico y social para permitir la erección de instituciones que, a su vez, puedan ordenar esos espacios, son los que, de una manera tan acertada como impresionista, describe Scott (1999).

6 «Una situación prácticamente confederal» es la expresión que emplea para referirse al punto de partida del Estado liberal tras la Primera Guerra Carlista. Pro (2019): 150.

7 Las relaciones entre poder central y poder local han sido analizadas de forma muy perspicaz y novedosa en diversos textos de Xosé Ramón Veiga. Véase, por ejemplo, su reflexión al hilo de la bibliografía reciente, en Veiga (2017). 
construcción del Estado. Lo que sí llama la atención es la brecha persistente entre, por una parte, la estructura legal y administrativa basada en el modelo francés, que aspiraba a ejercer un control intenso sobre el territorio y la sociedad, y, por otra parte, la realidad de un poder central débil ${ }^{8}$. Brecha persistente no quiere decir brecha estática. Hubo un proyecto de desarrollo administrativo que, no obstante la existencia de diversos modelos y las diferentes crisis que jalonaron su puesta en práctica, fue avanzando gradualmente.

En este contexto, los ingenieros ejercieron funciones clave en la construcción del Estado, entre ellas la de convertirse en un elemento de continuidad a través de las recurrentes crisis políticas y en un puente entre modelos estatales en pugna porque sus cuerpos lograron consolidarse con rasgos propios que les dotaban de una relativa autonomía y estabilidad, inexistente en una Administración sacudida por los cambios de Gobierno y sus oleadas de ceses y contrataciones de empleados públicos ${ }^{9}$. En sentido inverso, la propia configuración de la ingeniería se vio determinada por la centralidad de su papel político-administrativo. Desde mediados del siglo XIx los cuerpos de ingenieros llegaron a representar una visión particular del Estado como un ente encargado de promover el progreso material y el bienestar social mediante la eliminación de obstáculos a la riqueza nacional y la extracción de recursos para fomentar ese proceso de enriquecimiento colectivo.

Sin descuidar la extracción de las riquezas del espacio no cultivado (montes) y del subsuelo (minas), las obras públicas se convirtieron en todo un símbolo de la acción del Estado y, en consecuencia, en una herramienta para construir y reforzar su legitimidad. De la trascendencia de esa misión estaban convencidos los ingenieros de caminos:

Preciso es también atender con preferencia a la aplicación que de una parte de sus productos debe hacerse a las obras públicas: solo así recogerán los pueblos el fruto que legítimamente tienen derecho a esperar de ella. Esta misión, encomendada al señor ministro de Fomento, es acaso la más delicada, la que más tacto y asiduidad necesidad. El impulse de las vías férreas, la realización de los caminos vecinales, la construcción de otras obras de verdadera utilidad, son la base del Desarrollo y del progreso [...]. No es a la gloria de la actualidad; no es a un brillo pasajero a lo que debe aspirar el hombre que toma sobre si ese elevado cargo; sino a un renombre imperecedero, cimentado en las grandes

8 Sobre la negociación entre poderes locales y poder central: Krohn-Hansen y Nustad (2005).

9 Una visión global de la trayectoria de las diversas ingenierías, de Estado o no, en Silva Suárez (2007). 
obras de utilidad pública en el engrandecimiento de los pueblos, y en los progresos de las ciencias y de las artes ${ }^{10}$.

Efectivamente, a juzgar por los discursos que rodearon todos los actos relacionados con el Ministerio de Fomento, desde la apertura de las escuelas especiales hasta la inauguración de las líneas férreas, estos técnicos fueron investidos de un potencial transformador muy amplio. Los ingenieros españoles exploraron y explotaron esa gran capacidad de generar expectativas y deseos que, como apunta Brian Larkin, poseían las infraestructuras en los siglos XIX y XX, hasta el punto de convertirse en fetiches de la modernidad, además de llegar a ser uno de los elementos organizativos principales de la vida cotidiana de la época ${ }^{11}$. El ferrocarril, en particular, estaba cargado de expectativas de progreso, tanto a nivel de las regiones por las que iba a pasar, como en lo que concernía a la humanidad entera, como señalaba un órgano de prensa ministerial: «La construcción de ferro-carriles está llamada indudablemente á ejercer en la civilización del siglo XIX mayor influencia que han conseguido en muchos años los procesos de la ciencia, la propagación de ideas sociales y políticas, y la fuerza en fin de las armas que esta invención debe inutilizar con el tiempo»" ${ }^{12}$, o el literato, por entonces cercano al moderantismo, Pedro Antonio de Alarcón: «Pronto brotarán la industria y el comercio á la orilla del ferro-carril, y la civilización y la riqueza le saludarán a su paso, y la misma agricultura le reconocerá como auxiliar y amigo. Son dos gigantescos hermanos, iguales en poder y fecundidad, consagrado el uno por la historia de los tiempo y representante el otro de toda la grandeza de la civilización» ${ }^{13}$.

En este artículo defendemos la hipótesis de que, si bien es cierto que la inversión efectiva en proyectos de infraestructuras fue limitada y la capacidad pública de inventariar y movilizar recursos productivos se mantuvo en niveles bajos, la imagen del Estado como palanca potencial de la riqueza nacional, por medio de la obra pública y en menor medida de otros servicios de fuerte componente técnica y material, se extendió gradualmente a lo largo del siglo XIX entre la población y ha gozado desde entonces de una fuerza y longevidad notables. En nuestra opinión, esta idea del «Estado de obras públicas» ha tenido en la contemporaneidad una notable aceptación en todos los grupos políticos en España. De este modo, aspiramos a contribuir al debate que sigue vivo a nivel

10 "Misión del nuevo ministerio», Gaceta de los caminos de hierro, 4-7-1858

11 Larkin (2013).

12 La Ilustración, 17-3-1849.

13 Pedro Antonio de Alarcón: «Toledo. Inauguración del Ferro-carril. Bellas Artes», El Museo Universal, 20-6-1858. 
nacional e internacional sobre la supuesta debilidad del Estado construido en Espańa en el siglo XIX, aportando una vía interpretativa poco explorada que se nutre de una comparación amplia con otros países europeos ${ }^{14}$.

\section{EL INGENIERO COMO MODELO DEL EMPLEADO PÚBLICO}

La ingeniería es un campo de conocimiento y una práctica experta (o «facultativa», en el lenguaje de la época) que se reconfiguró como profesión moderna durante el siglo XIX. En Espańa, los cuerpos de ingenieros creados como parte del aparato del Estado emergente desempeñaron un papel clave en este proceso de definición profesional. Las ingenierías del Estado marcaron el desarrollo de la profesión en el incipiente sector privado, sobre todo al quedar vinculada la ingeniería con estudios superiores con alta carga teórica y al considerarse como una ocupación digna de un caballero, con su remuneración correspondiente. Tal y como se desarrolló dentro de las estructuras administrativas entre los años 1790 y 1900, la ingeniería española se asentó sobre dos tradiciones interconectadas. La primera consistió en una apropiación creativa de la organización administrativa francesa en los términos en que se fue configurando a partir de la Revolución francesa y el Imperio napoleónico. La Francia revolucionaria y postrevolucionaria sirvió como un punto de referencia para los reformistas españoles de distintos signos, aunque esta inspiración no siempre fuese reconocida. La segunda tradición, quizás más sólida, se remonta a más de cien años antes de la revolución liberal: el intervencionismo de la Corona española en el siglo XviII también se apropió de los modelos franceses que integraban, a su vez, prácticas e instituciones de la monarquía hispana, incluidas las que se desarrollaron en Flandes, en los dominios

14 La relación entre la ingeniería moderna y la transformación del poder político en los siglos XVIII y XIX, así como la emergencia de la ingeniería como profesión, han sido estudiadas por Gouzévitch y Verin (2005); Grelon y Gouzévitch (2007), y Brown et al. (2009). La idea de Estado español débil ha constituido un lugar común de la bibliografía politológica desde el artículo seminal de Linz (1973), que asociaba los problemas del Estado en España a la débil nacionalización en el marco de la teoría de la modernización. En años recientes una inmensa bibliografía sobre la construcción del Estado y sus limitaciones ha orientado los trabajos en otro sentido: estamos de acuerdo con Pro (2019) en que una discusión más productiva pasaría por estudiar el proceso de construcción del Estado, como hace este autor en su obra, en vez de centrarse la construcción de la nación que es un proceso entrelazado con el de la construcción del Estado, pero diferente, y desde luego no constituye un mero epifenómeno de la construcción estatal. 
italianos y en América. Los ingenieros del Ejército fueron organizados en un cuerpo a principios del siglo XVIII y la Real Armada creó su propio cuerpo de ingenieros en 1770. En ambos casos, los ingenieros recibieron una formación sistemática en matemáticas en academias creadas con este propósito. La Corona fue asumiendo cada vez más tareas durante la segunda mitad del siglo XVIII, dentro del discurso de fomento, entendido generalmente como un esfuerzo dirigido a aumentar la riqueza del reino y el afán de hacer su gobierno más eficaz. Como parte de este proceso, se creó una sección dentro del cuerpo de ingenieros del ejército encargada exclusivamente de obras civiles, sin relación directa con la guerra, como la construcción de puentes y caminos. Asimismo, las élites ilustradas de toda Europa, desde Portugal hasta Rusia, consideraban la hidráulica como un área de conocimiento y aplicación de gran importancia, esperando que la mejora del transporte fluvial, el regadío y la minería, todas ellas prácticas que podían beneficiarse de las innovaciones en ese campo, contribuyeran a una explotación más eficaz de los recursos. El triunfo del liberalismo en España en la década de 1830 integró este discurso dieciochesco de controlar y fomentar la riqueza del país en un marco radicalmente redefinido: el de gobernar la patria en el nombre de la nación y para su beneficio $^{15}$.

Los cuerpos civiles de ingenieros - el cuerpo de Caminos se creó en 1799, el de Minas en 1833, el de Montes de forma gradual en la década de 1850, mientras los ingenieros agrónomos consiguieron organizarse en un cuerpo de Estado en 1879- llegaron a convertirse en ejemplo de un aparato administrativo moderno. Su reputación y la representación que proyectaron de sí mismos se basaron en varios elementos. El punto clave era la visión del servicio público como acción racional fundada en conocimientos científicos certificados y orientada a promover el bien común. Los ingenieros del Estado hacían gala de los procedimientos meritocráticos a la hora de seleccionar a los aspirantes y durante su paso por las escuelas especiales, fundadas con el

15 Sobre el surgimiento y la transformación de las tradiciones de la ingeniería francesa y su relación con grandes cambios políticos, véase: Alder (1999). Para la Francia revolucionaria e imperial como referencia para los reformadores absolutistas españoles durante la Década Ominosa: Luis (2002). Sobre la frontera franco-flamenca como zona de innovación en la ingeniería militar y en la enseñanza técnica: Muller (1959) y Capel et al. (1988). Jean-Frédéric Schaub muestra cómo la circulación de modelos entre Espańa y Francia no fue un flujo unidireccional, apuntando a los orígenes españoles de varias instituciones y prácticas del absolutismo francés en el reinado de Luis XIV en Schaub (2003). Sobre el papel de las matemáticas en la formación de los ingenieros españoles: Capel et al. (1988); Massa-Esteve et al. (2011), y Ausejo (2007). Sobre las políticas de fomento en los imperios dieciochescos, Gouzévitch et al. (2017). 
propósito de formar facultativos para el Estado. Resaltaban que en los cuerpos el ascenso se producía mediante mecanismos impersonales (escalafón, promoción por antigüedad): "Los ascensos en el Cuerpo son por rigurosa antigüedad; y los servicios extraordinarios se premian por el Gobierno por los varios medios de que dispone sin contar los grados, que no puede conferir por actos espontáneos y voluntarios: así se evita la posibilidad de que a pretexto de premiar el mérito, y estimular el celo, se introduzcan el favoritismo con las intrigas y las injusticias que siempre le acompañan ${ }^{16}$.

Sin embargo, desde mediados del siglo xIx, los cuerpos y cargos facultativos (los ingenieros de caminos, los médicos-directores de baños y otros) fueron duramente criticados por su pretensión de monopolizar los puestos técnicos bien remunerados en la Administración pública y obstaculizar la iniciativa privada. Sus críticos desplegaron argumentos liberales para tacharlos de herederos privilegiados de los gremios del Antiguo Régimen ${ }^{17}$.

Si bien es cierto que existía cierta continuidad con las pautas de la organización del gobierno durante el Antiguo Régimen, los rasgos y las tareas de los cuerpos habían sido redefinidos y habían adquirido componentes radicalmente nuevos tras su refundación liberal. Había una diferencia fundamental entre los servidores del rey, por una parte, y los cuerpos facultativos, por otra. Desde la década de 1790, pero sobre todo a partir de la consolidación definitiva del régimen constitucional en la de 1830, la relación de los cuerpos con el gobierno fue definida por leyes y reglamentos detallados. De este modo, en vez de "postrarse a los pies de Su Majestad" para pedir su sueldo y el pago de dietas, como había sido habitual todavía entre los años 1790 y 1830, a mediados del siglo XIX los ingenieros pudieron reclamar sus derechos legales como empleados públicos con un lenguaje administrativo en el que se adivinaba una profunda confianza en sí mismos ${ }^{18}$. Los ingenieros del Estado

16 "Cuerpo de Ingenieros de Caminos, Canales, Puertos y Faros», Revista de Obras Públicas, 23 (1856), p. 267.

17 Martykánová (2016).

18 Para un ejemplo del primer tercio del siglo, en una carta a la superioridad del ingeniero Subercase, datada el 27-8-1815, este dirigiéndose formalmente al rey, decía: «Don Juan Subercase Ingeniero de Caminos y Canales, postrado a los reales pies de V. M. con el más profundo respeto expone: que habiendole destinado los Sres. Directores de Correos y Caminos á Villafranca del Vierzo para cuidar del trozo de camino comprendido entre Astorga y Lugo, les hizo presente en 22 de este mes que para llevar á debido efecto sus órdenes, necesitaba hacer gastos extraordinarios y excesivos para los cuales no alcansaba su corto sueldo: tales son un viage de 70 leguas con su muger enferma, un niño de tres ańos y sus muebles; la compra de un caballo con arreglo á las instrucciones de su empleo; y la adquisicion de algunas instrumentas y 
ocuparon una posición de alta carga simbólica, por excepcional que fueran sus condiciones de servicio en la Administración española de aquella época o más bien, incluso, por esa excepcionalidad. Teniendo en cuenta que sus derechos fueron definidos por ley y su admisión y permanencia en los cuerpos facultativos se regía por procedimientos impersonales, se encontraban protegidos frente a toda una serie de presiones y servidumbres a las que se enfrentaron tanto los empleados públicos como los cargos políticos en la época. Por lo tanto, pudieron mantener con cierta facilidad el discurso que les contraponía a quienes buscaban el interés particular, por muy legítimo que fuese tal búsqueda en una sociedad liberal. Al situarse en una posición aventajada a la hora de proyectar la imagen de representantes del bien común, particularmente equipados para ello, llegaron a identificarse con el Estado modélico, el defensor de los intereses generales, en un medio plagado de denuncias y críticas a la corrupción y al clientelismo imperantes en los aparatos públicos españoles. La figura del ingeniero como representante del Estado y, por ende, del bien común, destaca particularmente en contraste con la del cesante, empleado público que, al no formar parte de un cuerpo reglamentado, se hallaba a merced de los cambios de Gobierno y del capricho de los políticos, y pasaba largas temporadas desempleado, (mal)viviendo de una paga reducida hasta que su padrino o padrinos y el partido o la red en que se encuadraran volvieran al poder ${ }^{19}$.

Los ingenieros desempeñaron un papel clave en el desarrollo de nuevos recursos públicos y, al mismo tiempo, contribuyeron a crear, en palabras de Timothy Mitchell, «la autonomía aparente del Estado como una entidad independiente $»^{20}$. En primer lugar, los cuerpos de ingenieros introdujeron en el siglo XIX en la Administración civil muchos rasgos desarrollados durante el siglo XVIII en el Ejército para fomentar su eficacia. En segundo lugar, los ingenieros del Estado civiles (en el sentido de no militares) encarnaron un nuevo funcionariado civil que combinaba el conocimiento experto, la meritocracia, la disciplina y un alto grado de autogestión. En tercer lugar, al desempeñar sus tareas y funciones participaron en la acumulación de recursos, en la administración del territorio y en la creación de infraestructuras. Por último, los

libros costosos indispensables para el mejor desempeño de su obligacion [...]», $A M O P U$, leg. 6856, expediente de Juan Subercase y Krets.

19 Para las críticas decimonónicas de los cuerpos: Silva y Lusa (2007). Un análisis detallado de las actitudes de los ingenieros industriales: Lusa (1994). Sobre la continuidad y discontinuidad de los cuerpos facultativos con el Antiguo Régimen: Malatesta (2006).

20 Mitchell (1999). 
ingenieros del Estado y los que trabajaron en el sector privado — dos esferas que se definieron por oposición y, al mismo tiempo, estuvieron estrechamente ligadas - proyectaron conjuntamente una representación concreta del Estado: por medio de la regulación de la ingeniería en tanto que profesión y a través de su trabajo, contribuyeron a diferenciar lo público de las relaciones privadas en el mercado y fuera de él, es decir, de la sociedad civil. En sus prácticas encarnaron una nueva legitimidad del Estado como promotor del progreso. Esta imagen fue difundida y fomentada no solo por los ingenieros mismos, sino también desde a prensa general que abrazó con entusiasmo una visión del progreso ligada a la construcción de las grandes obras, enmarcándola en el afán patriótico de inscribir España entre las naciones de la Europa civilizada: «El gran Desarrollo que han tomado en España las obras públicas da ocasión a los ingenieros y arquitectos para mostrar los adelantos que han hecho en las construcciones poniéndose a nivel de las mejores de Europa. El Museo Universal, deseoso de impulsar el celo de los hombres científicos y de los contratistas, dará cabida en sus columnas a la descripción de las obras que más sobresalgan de este género» ${ }^{21}$.

Como empleados públicos, los ingenieros ejercieron una gran influencia sobre la definición y protección legal de sus campos de acción facultativa y sobre las formas válidas de acreditar la posesión de conocimientos científicos y técnicos. No dudaron en usar el aparato estatal para sus pugnas con otros grupos socioprofesionales. La consolidación de la ingeniería en los cuerpos del Estado, anterior en España a la consolidación de la ingeniería como una profesión liberal digna de hombres de cierto estatus en la sociedad, permitió a los ingenieros dar el salto hacia las actividades a caballo entre la esfera pública y la privada, fomentando el transvase de personas, conocimientos e influencias entre ambas, un fenómeno conocido en Francia como pantouflage pero que, significativamente, en España no recibió una denominación específica. Al mismo tiempo, las excedencias que los ingenieros del Estado negociaron con el fin de proseguir su carrera en uno u otro ámbito dibujaron una línea clara entre las dos esferas, pública y privada, lo que contribuyó a reforzar su definición y separación.

\section{LOS INGENIEROS Y LA CONSTRUCCIÓN DEL ESTADO EN ESPAÑA, $1835-1900$}

La monarquía constitucional que los patriotas empezaron a construir durante la guerra de Independencia y que los liberales consiguieron estabilizar

21 El Museo Universal, 7-7-1861. 
después del colapso del imperio español, al triunfar sobre las fuerzas contrarrevolucionarias en 1840, contaba con unas instituciones frágiles. Las estructuras administrativas creadas durante el siglo XviII para transformar la relación entre la Corona y sus dominios se habían visto seriamente dañadas por la pérdida de las posesiones transatlánticas en tierra firme americana, por las sucesivas revoluciones y restauraciones del viejo orden, por las purgas y exilios de los cargos administrativos y empleados públicos y por la caída dramática de los ingresos del erario público. A finales de la década de 1820 y durante la de 1830, los ministros reformistas del rey absoluto y las nuevas élites políticas a menudo volvieron la mirada hacia los logros y proyectos del reinado de Carlos III (1759-1788), en cuyo curso se habían dado grandes pasos hacia la construcción de una nueva monarquía española, basada en la centralización administrativa y política. Menos atractivo resultaba reivindicar el reinado de su hijo Carlos IV, que se percibía a través de las pugnas internas y externas que marcaron la crisis del Antiguo Régimen, pese a que en la década de 1790 y en la primera del nuevo siglo se habían adoptado medidas reformistas de gran calado, también en el campo de caminos y canales, que nos concierne en este artículo.

El Estado nacional en construcción necesitaba reafirmar y expandir su poder sobre el reino, sus tierras y sus habitantes, definidos ahora por las constituciones liberales en términos políticos como "el territorio nacional español» y «los españoles», así como sobre los restos ultramarinos del imperio, definitivamente transformados en 1837 en colonias ${ }^{22}$. Convertir los diferentes espacios que seguían bajo soberanía de la monarquía en el territorio nacional y el heterogéneo entramado de comunidades metropolitanas en la sociedad española eran tareas que requerían adquirir un control político real y eficaz. Este tipo de control - a diferencia del que el centro ejercía sobre los espacios locales durante el Antiguo Régimen - precisaba de la acumulación de conocimiento en las instancias administrativas centrales. Reunir información gráfica, cuantitativa y cualitativa sobre el país y las colonias era el propósito declarado de las representaciones cartográficas y de la información cuantitativa estática y, sobre todo, seriada, cuyo desarrollo debía ser encomendado a instituciones permanentes. Sin embargo, resultaba costoso crear las instituciones geográficas y estadísticas que pudieran proporcionar esa información considerada imprescindible para la

22 Fradera (2005). No podemos dedicar suficiente atención en este texto a la ingeniería española en las colonias, pese a que no constituían ni mucho menos un espacio irrelevante para la construcción del Estado nacional (empezando por su elevada contribución a los ingresos fiscales) ni para la sociedad metropolitana ni, desde luego, para los diversos cuerpos y profesiones ingenieriles. 
correcta lectura del territorio y la población nacionales. Es más, era un proceso políticamente arriesgado y controvertido, dadas sus implicaciones para la gestión política de recursos ${ }^{23}$. De hecho, la consolidación definitiva de las instituciones en cuyo marco se debía avanzar en estas prácticas técnico-administrativas solo fue posible a partir de la Revolución Gloriosa de 1868, e incluso entonces con serias deficiencias. En el Sexenio se creó el Instituto Geográfico y Catastral, que empleó a ingenieros militares y civiles asistidos por topógrafos. Los ingenieros militares, en particular, estuvieron detrás de diversas iniciativas de las tres décadas anteriores, encaminadas al desarrollo de una cartografía científica. La Comisión para el Mapa de España, creada por el Estado Mayor del Ejército en 1843, estaba compuesta ante todo por ingenieros militares y oficiales de la Real Armada, a los que se les unieron en 1850 los ingenieros de caminos, minas y montes, ya que entre las tareas de estos cuerpos estaba la de hacer mapas como parte de sus proyectos de obras públicas (caminos), preparar mapas geológicos (minas) y forestales (montes) ${ }^{24}$.

En cuanto a la estadística, la contribución de los ingenieros del Estado fue menor. Aun así, generaron datos cuantitativos relativos a su campo de acción y, a pesar de los problemas de fiabilidad de las cifras que obtuvieron, sus datos sirvieron de base para varias de las pocas series estadísticas continuas de la España decimonónica (caminos y ferrocarriles en construcción y terminados, producción minera y contabilidad presupuestaria). La estadística fue esencial a la hora de justificar la creación en 1879 del cuerpo de ingenieros agrónomos, siguiendo el modelo de los cuerpos de ingenieros ya existentes. El decreto de bases del Servicio Agronómico afirmaba en su artículo 2.०: «El objeto de este servicio será ejecutar todos los trabajos de Estadística agrícola y pecuaria $»^{25}$. En ese mismo año, 1879, se dieron los pasos definitivos hacia una unificación de los pesos y medidas que, pese a los diferentes intentos anteriores y pese a la presión de los técnicos del Estado, había sido combatida con éxito durante casi tres décadas por parte de las autoridades locales y de la población ${ }^{26}$.

Además de coleccionar y tratar recursos en forma de información, los ingenieros contribuyeron también a proveer al Estado de ingresos financieros

23 Pro $(1994,2019)$.

24 Muro y Casals (2011).

25 Sobre la nueva definición del Estado español en las constituciones liberales véase Pro (2019). Sobre la comisión del mapa de España: Muro et al. (1996). Las estadísticas como una de las tareas centrales que justificaron la creación del cuerpo de ingenieros agrónomos en Pan-Montojo (2005).

26 Aznar (2011). 
directos e indirectos. En el caso concreto de la minería, los ingenieros de minas se encargaron de determinar las bases tributarias del impuesto de este ramo. Los ingenieros también se encargaron de la gestión permanente de determinados bienes públicos: los ingenieros de minas dirigieron las minas públicas, los ingenieros navales y militares las fábricas de armas y arsenales públicos, y los ingenieros de montes supervisaron la explotación de los montes públicos, estableciendo las condiciones para su concesión a compañías privadas y a particulares. Además, la provisión indirecta de recursos era la base de toda la concepción del fomento. Los ingenieros de caminos proyectaron y ejecutaron o supervisaron la ejecución de las obras públicas que incluían la inmensa mayoría de las infraestructuras de transporte terrestre y marítimo, de gran riego y de abastecimiento de agua a las ciudades. De este modo, no solo se echaban sobre los hombros la garantía de un gasto eficaz de los dineros públicos. Al ampliar y modernizar las infraestructuras, se entendía que los ingenieros ponían las bases del progreso material, con el significado que a estos términos otorgaban las élites políticas y sociales de la época. Hubo un consenso amplio de que así fomentaban la riqueza de España, incrementando los ingresos del Estado y fortaleciendo las instituciones públicas. Nos encontramos con esta línea de razonamiento en muchos textos legales y políticos de la España decimonónica. Por tanto, podemos suponer que, fuera cual fuera la contribución real de las obras públicas al desarrollo de las distintas actividades económicas y fuera cual fuera la elasticidad de la tributación (más bien baja en un sistema fiscal poco flexible y fundado en la negociación), los observadores políticos contemporáneos percibían la ingeniería como un mecanismo administrativo creador de recursos ${ }^{27}$.

Información, dinero y recursos materiales se combinaron con recursos políticos. Como ha observado Germà Bel, la regulación y el desarrollo de los flujos dentro del territorio nacional constituían el objetivo principal de la acción política en materia de infraestructuras, una de cuyas directrices era la centralización de las vías de comunicación en la capital del Estado y, de forma secundaria, en las ciudades capitales de provincias, y asegurar así la máxima movilidad de los funcionarios y las órdenes administrativas y una rápida movilización de las fuerzas militares ${ }^{28}$. Los nuevos caminos construidos en las décadas de 1840 y 1850 siguieron un trazado radial desde Madrid a los puertos principales en las costas, sobre la base del que había sido diseñado en el

27 Respecto a los ingenieros de minas y su papel como agentes del Estado: Chastagnaret (2000). En relación a los de montes: Gómez Mendoza (1992) y Casals (1996). Respecto a los ingenieros de caminos: Ferri (2015).

28

Bel (2015). 
siglo XVIII ${ }^{29}$. Esta red fue completada en cada una de las 47 provincias peninsulares creadas en 1833 por una red de carreteras secundarias con su centro en las capitales provinciales, escogidas por una combinación de razones políticas y socioeconómicas $^{30}$. Las líneas férreas siguieron un esquema muy similar. Su plan - un término nuevo empleado para las obras públicas que apunta hacia un imaginario muy particular, una mente que lo diseña y coincidente con el Estado- y la organización del territorio resultante buscaban fomentar los recursos políticos, militares y culturales del Estado. Al mismo tiempo se sobrentendía, aunque con poca reflexión explícita, que las infraestructuras hacían posible la consolidación de la nación y, de este modo, la legitimidad del poder político que respondía a la soberanía nacional o a esta y a la histórica de la Corona. La Ley de Enajenación Forzosa de 21 de julio 1836 declaró que las obras públicas eran una de las responsabilidades principales del Estado. Al mismo tiempo definió público como un concepto que hacía referencia tanto a los responsables de estos proyectos —el Estado y sus agentes - como a los que se beneficiaron de ellos, es decir, el público en el sentido de ciudadanía o pueblo. $\mathrm{Al}$ ejercer sus tareas profesionales, los ingenieros del Estado, civiles y militares, se convertían así en fuerzas al servicio de toda la comunidad nacional ${ }^{31}$.

España participó desde fechas tempranas en la configuración transnacional del liberalismo y en los años 1840 adoptó el modelo francés de Administración central ${ }^{32}$. La definitiva consolidación casi desde los inicios de la hegemonía liberal de varios servicios facultativos del Estado, entre los que destacaban los cuerpos de ingenieros, no estuvieron acompañadas de un gasto público que correspondiese a la importancia que se atribuía al fomento de la riqueza colectiva. La debilidad de las élites políticas nacionales requería además la negociación del centro con las oligarquías locales, un proceso multiforme en el que el conocimiento de los recursos territoriales era un elemento clave para ambas partes. La creación y consolidación de instituciones dedicadas a la cartografía y estadística fueron obstaculizadas por fuerzas que se resistían a un control directo del Gobierno y sus representantes en cada provincia y la recaudación de impuestos tuvo que ser subcontratada a las

\section{Madrazo (1984).}

30 Sobre la elección de las capitales provinciales y su impacto territorial: Burgueño (1996).

31 Bel (2011). Respecto a cómo la planificación tenía por objetivo la construcción nacional en Portugal y en otros países, véase Macedo (2012). La construcción discursiva y jurídica de las obras públicas como función estatal: Rosado (2000).

32 Pro $(2017,2019)$. La descripción de la concepción francesa del Estado y de su modelo administrativo en Rosanvallon (1990). 
autoridades locales y provinciales, una opción que tuvo un reflejo en la propia legislación general ${ }^{33}$. Se hizo difícil poner en marcha mecanismos fiscales autónomos, lo que limitó los ingresos del Estado y su flexibilidad en el sentido de capacidad de que la recaudación aumentase de forma automática al crecer la renta nacional.

TABLA 1. Gasto público*/renta nacional

\begin{tabular}{cccccc}
\hline & Reino Unido & Italia & Francia & Alemania & España \\
\hline 1850 & 12,4 & - & 8,5 & - & 5,9 \\
\hline 1860 & 12,7 & 14,6 & 9,1 & - & 8,0 \\
\hline 1870 & 9,9 & 15,4 & 11,6 & 18,5 & 10,3 \\
\hline 1880 & 10,4 & 13,1 & 15,4 & 12,5 & 8,5 \\
\hline 1890 & 10,3 & 17,3 & 15 & 15,2 & 8,5 \\
\hline 1900 & 16,9 & 15,2 & 15,2 & 17,4 & 7,5 \\
\hline 1910 & 14,5 & 17,8 & 14,4 & 16,7 & 8,3 \\
\hline 1920 & 31,8 & 42,8 & 37,6 & 28,9 & 8,3 \\
\hline 1930 & 29,4 & 24,5 & 24,6 & 43,1 & 9,7 \\
\hline
\end{tabular}

* Gasto público de todas las Administraciones públicas, excepto en Italia y España, donde solo se cuenta el gasto de la Administración central ${ }^{34}$.

Comparando el gasto público total, observamos no solo que España se situaba por detrás de países como el Reino Unido, Francia y Alemania, que hacia 1870, disfrutaban de una renta per cápita muy superior a la española, divergencia que había crecido en 1900, sino que lo mismo ocurría si el punto de referencia es Italia, un Estado nuevo cuya renta per cápita en la segunda mitad del xix era bastante semejante a la de España. No solo la cuantía total de los gastos públicos era más baja, sino que la estructura del gasto público no indica una implicación activa del Estado en el fomento de la riqueza pública: antes de 1870 , los rasgos distintivos del presupuesto del Estado en Espańa eran un alto porcentaje del gasto militar $(26,4 \%$ en 1850 y $34,5 \%$ en 1860) y, desde 1870 en adelante, un alto porcentaje

33 Pan-Montojo (2007).

34 Comín (1996): 150. 
destinado a pagar los intereses de la deuda pública $(52,7 \%$ en $1870 ; 38,1$ $\%$ en $1880 ; 34,7 \%$ en $1890 ; 43,9 \%$ en $1900 ; 36,1 \%$ en 1910 e incluso, en la década 1920, porcentajes parecidos a los de aquellos países que, a diferencia de España, sí participaron en la Gran Guerra y heredaron un endeudamiento elevado).

En relación con el gasto público total, lo dedicado a agricultura (incluidos los montes) y obras públicas (ferrocarriles, caminos y puertos) era poco en términos relativos, un $8 \%$ de promedio durante todo el periodo analizado, y marcado por ciclos breves dentro de una tendencia de aumento moderado a largo plazo (gráfico 1). Cabe destacar que en los presupuestos para 1862-63 y 1863-64, durante el Gobierno de O’Donnell, el gasto en obras públicas aumentó hasta casi el $10 \%$ de todo el gasto público, un porcentaje que además no hace justica a la cantidad real, probablemente alrededor del $15 \%$, ya que los subvenciones al ferrocarril se canalizaron a través de la deuda pública y no se incluían en el presupuesto. Por esta razón, la década de 1860 ha sido bautizada por la historiografía como la edad de oro de las obras públicas. La Unión Liberal de O'Donnell compartió con el fontismo portugués una visión de las obras públicas, sobre todo de la construcción de carreteras y ferrocarriles, como la vía fundamental para conseguir a corto plazo el progreso material y sus Gobiernos se mostraron dispuestos a invertir muchos más recursos que sus predecesores o sucesores decimonónicos en este ramo. No obstante, a pesar de este periodo excepcional y de la dificultad de hacer una estimación sobre las obras públicas pagadas o subvencionadas por las autoridades provinciales y municipales, en general el Estado gastaba en España en obras públicas y en otros servicios económicos menos que el Reino Unido, Alemania y Francia y bastante menos que Italia. De nuevo, la diferencia entre España e Italia es particularmente llamativa, por lo parecidas que eran las condiciones económicas de ambos países. Mientras que en la nueva monarquía mediterránea «hacer italianos» y legitimar el novísimo Estado unitario tuvo un reflejo claro en la cantidad de dinero destinada a las obras públicas, en la vieja monarquía española, por muy nuevo que fuese el Estado nacional, el ramo de fomento no fue una prioridad en un presupuesto en el que pesaba mucho la deuda pública, ya que superar las rigideces fiscales resultaba imposible por razones políticas y las razones políticas eran difíciles de transformar por la ausencia de recursos fiscales ${ }^{35}$.

35 Un análisis del gasto público español en términos comparativos en Comín (1996): 147-165. Sobre la inversión en obras públicas y otros servicios económicos, véase la página 151. También sobre el gasto en obras públicas: Cuéllar (2002). Respecto al fontismo en Portugal: Fernandes (2001). 
Gráfico 1. Gasto en servicios económicos ${ }^{36}$

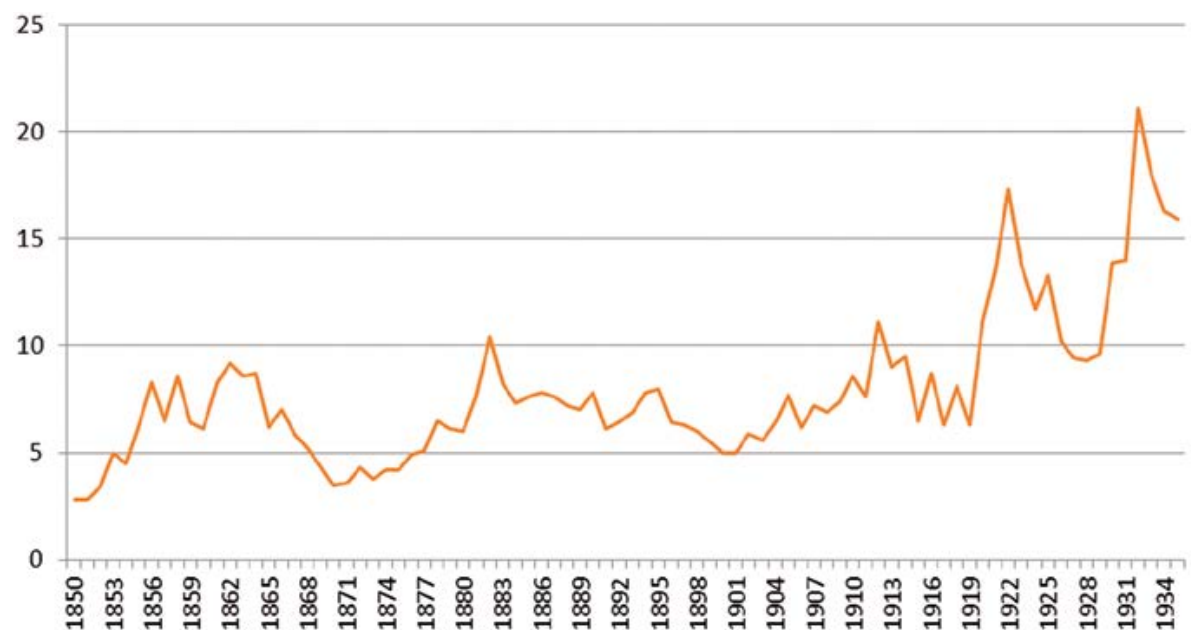

Las bajas tasas de gasto en obras públicas hasta después de 1898, y en especial hasta la reanudación de los proyectos aparcados por la Gran Guerra y sobre todo hasta los ambiciosos planes de la dictadura de Primo de Rivera, tuvieron consecuencias directas para la integración territorial del país y muy probablemente también para su construcción nacional, aunque no fuera el único factor en el asunto. Como muestra la tabla 2, las líneas férreas en España eran menos densas que en los países vecinos, aunque el dato sobre kilómetros de ferrocarril por cada mil personas revela que la baja densidad de la red no se debía únicamente a consideraciones presupuestarias, sino también a razones económicas que desbordaban las cuentas públicas: en 1866, cuando había sido puesta en funcionamiento una parte considerable de los nuevos ferrocarriles, ya quedaba claro que no existía suficiente demanda para que las compañías que los operaban pudieran sacar beneficio ${ }^{37}$.

Sin embargo, la falta de demanda en un país pobre y escasamente poblado no lo explica todo. Algunos historiadores económicos han afirmado que la distribución de la red ferroviaria, moldeada en gran medida por criterios políticos, reducía la demanda de los servicios ferroviarios debido a que no respondía a los flujos comerciales existentes. En el siglo xix esta tesis fue defendida por pocos, pero desde el principio del siglo xx atribuir el uso limitado de los ferrocarriles a la ausencia de vías y ramales secundarios, al mal

\footnotetext{
36 Comín y Díaz (2005).

37 Véase a este respecto el artículo de Barquín y Larrinaga en este mismo número.
} 
estado de los caminos vecinales o a la inexistencia de carreteras transitables que conectaran los pueblos con los caminos principales o llevaran a la estación de tren más cercana llegó a ser una crítica muy habitual ${ }^{38}$.

TABLA 2. Kilómetros de ferrocarril por pais ${ }^{39}$

\begin{tabular}{cccccc}
\hline \multicolumn{5}{c}{ Kms. de ferrocarril por 1000} & $\mathrm{~km}^{2}$ de superficie del pais \\
\hline & Francia & Alemania & Reino Unido & Italia & España \\
\hline c. 1850 & 5 & 11 & 43 & 2 & 0 \\
\hline c. 1870 & 25 & 34 & 94 & 22 & 11 \\
\hline c. 1890 & 59 & 77 & 121 & 47 & 18 \\
\hline c. 1910 & 64 & 110 & 140 & 63 & 22 \\
\hline \multicolumn{7}{c}{ Kms. de ferrocarril por 100000 habitantes } \\
\hline c. 1850 & 8 & Alemania & Reino Unido & Italia & España \\
\hline c. 1870 & 43 & 18 & 48 & 3 & 0 \\
\hline c. 1890 & 98 & 87 & 83 & 24 & 34 \\
\hline c. 1910 & 103 & 94 & 79 & 54 & 52 \\
\hline
\end{tabular}

Además de la baja densidad de las vías férreas, no se dedicaron apenas fondos a fomentar el riego en un país en el que las precipitaciones escaseaban y eran muy variables de año a año, como denunciarían los discursos costistas a partir del $98^{40}$. La inversión en puertos tampoco fue elevada en una península con una gran flota pesquera ${ }^{41}$. Por su parte, menos de 9.000 hectáreas fueron reforestadas hasta el año 1900 a pesar de que muchos bosques habían sido

38 Quizá no el primero, pero sí el más conocido de los argumentos sobre la falta de correspondencia entre la red ferroviaria y los flujos geográficos de mercancías fue desarrollado por Nadal (1975). Una visión actualizada de los planteamientos ingenieriles sobre el sistema terrestre de comunicaciones y sus carencias en Aguilar (2013).

39 Mitchell (1975) y Gómez Mendoza y San Román (2005).

40 Ortí (1996).

41 Frax (1981). 
arrasados tras la desamortización civil ${ }^{42}$. Miremos donde miremos, observamos que en las infraestructuras y servicios económicos España iba detrás de todos los países de la Europa Occidental con la excepción de Portugal. Hacia 1900 había una clara divergencia entre el discurso público de fomento, plasmado en la importancia atribuida a las obras públicas y a los bienes públicos en general, y el peso político y administrativo de los ingenieros, por una parte, y sus logros materiales limitados, por otra. Si bien es cierto que esta brecha fue disminuyendo en las tres décadas siguientes, en especial a partir de 1920, la realidad es que siguió siendo grande ${ }^{43}$.

\section{EL ESTADO EN OBRAS: LAS TAREAS, PRÁCTICAS Y REPRESENTACIONES DE LOS INGENIEROS}

Las paradojas de la ingeniería española se resuelven parcialmente si tenemos en cuenta, en línea con lo señalado en la introducción, que el Estado no es solamente un conjunto de instituciones administrativas más o menos coordinadas que gobiernan el territorio y su población en el nombre de la nación. Es también una idea, una representación de un todo unido y coherente que debe velar por una comunidad nacional imaginada, por la nación en la que se fundamenta. Es este último ámbito en el que los ingenieros españoles, a pesar del impacto limitado de su práctica profesional, desempeńaron un papel decisivo a lo largo de la segunda mitad del siglo XIx, sembrando lo que iban a cosechar en el siglo xx. Lograron hacerse reconocer como la encarnación de la ciencia útil, es decir, de la ciencia que podía y debía aplicarse al bienestar nacional, a la utilidad colectiva. Debido a los procedimientos de su selección, formación y promoción, que eran excepcionales dentro de la Administración española, y por su actividad profesional, tanto al servicio del Estado como en el sector privado, pudieron reconocersey ser reconocidos como nuevos hombres dotados de voluntad y conocimientos necesarios para fomentar el progreso material, identificado en la Espańa decimonónica como el espíritu del siglo (l’esprit du siècle, como a menudo se decía en francés). Es más, igual que los ingenieros hacían un buen uso de la plataforma que les ofrecían los puestos públicos en las capitales a la hora de promover su agenda corporativa y sus intereses económicos particulares, el Estado también se beneficiaba de la presencia, prácticas y discurso de los ingenieros ${ }^{44}$.

42 Gómez Mendoza (1992).

43 Sobre la evaluación pesimista de los logros del Estado en el siglo xix por parte de la opinión pública finisecular, véase Pan-Montojo (2006).

44 Martykánová (2016). 
Para empezar, los ingenieros representaron la acción del Estado de una forma muy específica: no recaudaban impuestos ni reclutaban hombres ni estaban en los pueblos para imponer las nuevas leyes, a diferencia de los empleados de Hacienda, de los oficiales del Ejército, de los guardias civiles o de los jueces, los representantes más ubicuos de la autoridad del Estado. Sin embargo, eran fáciles de identificar como representantes del poder estatal porque llevaban uniforme y tenían símbolos y emblemas que adornaban sus obras y sus edificios ${ }^{45}$. Además, se caracterizaron por una serie de comportamientos en público que garantizaban que todos les reconocieran en su posición oficial y superior: el desplazamiento a caballo, su preocupación por evitar el trabajo manual, su forma de vestir como caballeros y también cierta arrogancia comentada en las fuentes de la época ${ }^{46}$. Estos rasgos, muy parecidos a los que caracterizaban a los oficiales del Ejército, distinguían a estos hombres que hacían mediciones, examinaban el entorno y tomaban notas en sus cuadernos de campo de cuanto veían, levantaban planos, dibujaban mapas, redactaban informes y proyectos, dirigían o supervisaban la construcción de una nueva infraestructura (puentes, ferrocarriles, faros, suministro de agua, canales) o anunciaban la existencia de una veta o de un yacimiento con futuro. Además, publicaban estudios científicos en revistas especializadas y pronunciaban conferencias para el público urbano en los que no solamente explicaban lo que debía hacerse para resolver problemas concretos, sino lo que se estaba haciendo en este sentido en Europa.

Sin embargo, durante la mayor parte del siglo xix los ingenieros no fueron la cara buena del Estado, al menos no para la gran parte de la población. Si bien es cierto que no recaudaban impuestos, sí que con sus estudios topográficos o sus valoraciones del suelo o de los yacimientos allanaban el camino para las intervenciones fiscales; no reclutaban soldados, pero sí que hacían uso de ellos, además de recurrir a los presos comunes y a los vecinos para llevar a cabo las obras; no se encargaban de imponer la ley, pero sí tomaban partido en los conflictos o denunciaban a los guardas forestales o a la guardia civil a quienes infringían las normas administrativas. Para los que los conocieron personalmente no cabía duda de que eran miembros de la élite social y que además encarnaban un poder extraño y temido. Asimismo, hablaban otro idioma, unas veces literalmente pues se expresaban en castellano frente a las lenguas de sus interlocutores y, cuando el castellano era el

Sobre los uniformes y otros símbolos: Silva (1999).

46 Sobre la negociación del estatus social mediante una gestión cautelosa de la práctica profesional: Martykánová (2018). Para la representación en la literatura: Ordóñez (2007). 
idioma común de administradores y administrados, en un lenguaje apenas comprensible para sus interlocutores por estar lleno de jerga técnica y jurídica. Tenían el poder de imponer la expropiación de terrenos y casas, la venta pública o el uso restringido de bienes comunes, la elevación de la valoración tributaria de minas o tierras que podía llevar a impuestos más altos o la introducción de cambios en los sistemas de riego. Las autoridades locales también temían la intervención de los ingenieros y sus propuestas y en ocasiones expresaron su descontento de forma violenta, igual que ocurrió en Portugal $y$ en otros lugares ${ }^{47}$. No en vano el uniforme de campo de los ingenieros de montes incluía una pistola. Sin embargo, dado el número de los ingenieros y el hecho de que solieran residir en las ciudades (salvo una parte de los de minas y montes) y el alcance espacial limitado de sus actividades, para la inmensa mayoría de la población probablemente no tuviesen una imagen concreta y el término resultase únicamente asociado con el Estado y la ciudad, es decir, con el poder. A su vez, el público a los que se dirigieron los ingenieros no fue, hasta el siglo xx, la sociedad en general, sino lo que se llamaba opinión pública, es decir, las clases altas y medias que leían la prensa y participaban en política de forma activa o pasiva. Los "propietarios», los dueños de fábricas, las directores y accionistas de las compañías mineras, los políticos y profesionales como los abogados, los médicos, los notarios y los farmacéuticos y otros círculos socialmente poderosos constituían la audiencia a la que los ingenieros aspiraron a convencer de sus conocimientos expertos, de su capacidad de mejorar las infraestructuras, de introducir innovaciones técnicas, de superar los obstáculos e impedir los desastres naturales y de promover el progreso, ofreciendo nuevas soluciones a los problemas de la producción ${ }^{48}$. Al promocionarse a sí mismos como grupo profesional y como individuos, los ingenieros promovieron una nueva concepción del Estado para el que en su mayoría trabajaban, habían trabajado o aspiraban a trabajar al menos en algún periodo de sus vidas. Asimismo, contribuyeron decisivamente a construir la reputación de las escuelas especiales, fundadas, financiadas y operadas por el Estado, que los habían formado y que les habían proporcionado sus credenciales de expertos. Conforme fue avanzando el siglo XIX, la carrera de ingeniero, que había quedado inexorablemente vinculada con estudios superiores en esos centros especiales, se fue convirtiendo en una de las más prestigiosas de España.

\footnotetext{
Sobre las reacciones violentas en Portugal: Branco (2009).

48 Como subraya Pan-Montojo (2005), en relación con los ingenieros agrónomos y sus discursos sobre la agricultura que, únicamente a partir de 1900, empiezan a tener en cuenta a los cultivadores reales.
} 
En cierto sentido, las obras públicas llegaron a ser el bien común por excelencia y uno de los principales objetivos de la acción providencial del nuevo estado nacional del liberalismo y, de este modo, los ingenieros se convirtieron en la encarnación visible del proyecto del Estado. Varios factores influyeron en la centralidad de las obras y servicios públicos y de los ingenieros en la construcción del Estado idea en España. En primer lugar, situar el fomento en el centro de la acción estatal conectaba con una tradición potente del reformismo que se remontaba, al menos, a la monarquía católica dieciochesca. Además, existían pocas alternativas viables para legitimar el nuevo orden. El papel secundario de España en la arena internacional era un gran obstáculo a la hora de desarrollar una política internacional de prestigio (que solo acometió con escasos resultados la Unión Liberal, el partido que también protagonizó la edad de oro de las obras públicas entre 1858 y 1863), particularmente si comparamos la monarquía liberal con la monarquía católica transatlántica. La posición dominante de la Iglesia católica en un sistema político confesional hizo muy difícil que fueran las políticas culturales y educativas las que se convirtieran en la piedra angular de los proyectos de construcción del Estado nacional. El progreso material fomentado por el Estado vino, por ello, a constituirse en la bandera del buen gobierno tanto para los moderados como para los progresistas y para los dos partidos dinásticos en la Restauración e incluso para un republicanismo que, sin embargo, y a diferencia de los anteriores, condicionaba el triunfo del progreso material a una profunda transformación político-cultural, a la construcción de una nueva ciudadanía ${ }^{49}$. De modo poco sorprendente, para estos hombres políticos liberales, el progreso material se miraba en el espejo de los rasgos de los ingenieros, hombres de élite al servicio del Estado, y de sus obras: las infraestructuras mediante las que el Estado aparecía como actor de la modernización y difusor del conocimiento útil con una base cientifica. La ciencia útil, la ingeniería, se hallaba encarnada en unos caballeros con formación teórica y que se presentaban en sociedad como artífices del progreso y supervisores de los trabajadores al servicio del espíritu del siglo. El término ingenierismo, entendido como valorar la acción pública en términos de caminos, ferrocarriles, planificación urbanística, abastecimiento de agua, riego, puertos y divulgación técnica, es decir, contribuciones tecnológicas, universales y permanentes a la estructura material del país, sin tener a menudo en cuenta sus costes financieros, por no hablar de sus costes medioambientales o culturales, o sin reparar en las verdaderas necesidades de la mayoría de la sociedad, acabaría sirviendo, con connotaciones peyorativas, a la crítica de determinadas concepciones del poder en la España del siglo xx. En nuestra

49 Pan-Montojo (2014) y Peyrou (2008). 
opinión, fue al menos en parte debido a que los ingenieros habían radicalizado y ampliado su discurso decimonónico de fomento en uno superior que oponía el concepto de la acción política como obra y servicio públicos, como contribución a la comunidad, supuestamente más noble por tecnocrática y desinteresada, al mundo contaminado y contaminante de la política "de partidos» y a las "peligrosas utopías» revolucionarias.

¿Cuánto éxito tuvieron los ingenieros a la hora de difundir y encarnar el discurso de fomento a finales del siglo xix? Javier Ordóńez, Juan Carlos Ara y Javier Fornieles han mostrado que, mientras que la figura de ingeniero sirvió básicamente como símbolo de progreso y pensamiento racional en la literatura española de la época, su trabajo cotidiano, incluso su trabajo en las grandes obras, despertaba poco interés entre los literatos y fue prácticamente invisible. Añadamos que el ingeniero en ocasiones desempeñó un papel trágico en las historias nacionales de amor de la España decimonónica. Así, por ejemplo, en la obra de Benito Pérez Galdós, los ingenieros eran héroes al estilo de Prometeo que sufrían profundamente debido a sus relaciones amorosas con las mujeres, ya que ellas y/o sus familias representaron una España retrógrada, supersticiosa y corrupta. Estas relaciones, que desembocaron en la muerte o en el exilio del héroe, conforme con la visión trágica de dos Españas, es decir, un país unido en carne y sangre, pero dividido en dos grupos ideológicos divergentes, condenados a enfrentarse permanentemente en una lucha fratricida ${ }^{50}$. Por supuesto, las potentes imágenes creadas por Galdós no suponen que los ingenieros se situaran por fuerza en términos políticos en el liberalismo más laico ni, mucho menos, en la izquierda. Pero es verdad que los alineamientos con el carlismo o con el socialismo fueron excepcionales: todo apunta a que el grueso de los técnicos se colocaron en el espacio, mayoritario en las elites, del liberalismo respetable y, a lo sumo, en las filas del republicanismo. Si bien es cierto que los ingenieros se identificaron sin problemas tanto con esta imagen heroica de hombres modernos, como con la imagen de los forjadores del progreso material, para entender mejor el carácter polifacético de la imagen pública del ingeniero en aquella época haría falta, sin embargo, analizar sistemáticamente fuentes como la prensa general y la correspondencia privada ${ }^{51}$.

50 Esta interpretación la tomamos prestada de Sommer (2009). Su aplicación al análisis de los personajes vinculados con la ingeniería que aparecen en la ficción española de la época: Martykánová (2017). Una mirada renovada a la construcción intelectual de las dos Españas en Juliá (2004).

51 Sobre las dimensiones simbólicas de la figura del ingeniero en la literatura española: Ordóńez (2007); Ara Torralba (2007), y Fornieles (1989). 


\section{CONCLUSIONES}

En la España del siglo xix surgió una representación social particular: la de una relación cercana entre las políticas públicas, el cambio tecnológico y los ingenieros como profesión. Los ingenieros llegaron a encarnar el ideal de un Estado fuerte y eficiente, que usaba los conocimientos técnico-científicos para el progreso general de la nación. Esta representación nunca se mostró incompatible con la participación individual de los ingenieros en las luchas políticas ni con su integración a título individual en las redes de interés económico que conectaron los sectores público y privado, a pesar de la creciente separación simbólica de ambos. El prestigio de los ingenieros se basó en su proceso de selección, sus conocimientos presentados como útiles y su posición oficial en el aparato administrativo. En su conjunto, estos rasgos dieron lugar a un hombre nuevo que era capaz de evocar y representar los atributos de los distinguidos miembros de las corporaciones privilegiadas, construidas en el tiempo en el que los ingenieros debían luchar por el bien común en el nombre del soberano y, al mismo tiempo, manifestar todas las virtudes de un aristócrata benévolo y generoso, dispuesto al sacrificio personal en aras del progreso nacional. Como era de esperar, esta combinación ideal de viejos y nuevos valores no funcionó sin contradicciones y tuvo que ser defendida de forma activa en la palestra pública.

La imagen de un «Estado de obras públicas» que se empezó a fraguar en los 1830 no se tradujo en términos presupuestarios hasta el siglo xx. En España, los recursos fiscales relativamente escasos, que reflejaban el limitado poder infraestructural del Estado, lastraron a las instituciones públicas a la hora de financiar o coordinar la provisión de bienes públicos, particularmente las obras públicas, en comparación con otros países europeos. Los mecanismos fiscales eran insuficientes porque la clase política dominante careció de la voluntad de buscar vías para su transformación, como tampoco la hubo para promover instituciones educativas de un alcance más amplio. Ahora bien, incluso con otras coaliciones sociopolíticas que hubieran hecho posibles más, más eficaces y más duraderas reformas, no cabe duda de que la pobreza del país constituía un factor limitante.

Sin embargo, como hemos argumentado, la pobreza relativa no fue el único factor que restringió el gasto público: con una renta per cápita parecida a la de España, los Gobiernos nacionales de algunos otros países ordenaron las prioridades presupuestarias de forma diferente. La paradoja en el caso español consiste en que mientras las élites políticas y sociales compartieron con las élites de otros países periféricos la fe en la importancia de las infraestructuras y en el papel que los expertos técnicos podían desempeñar a la hora de superar 
la brecha de riqueza creciente entre sus países y las potencias dominantes del momento, no hicieron del gasto en infraestructuras su prioridad en sus políticas presupuestarias. Esta paradoja es aún más patente teniendo en cuenta el hecho de que el ingeniero, una figura social (re)creada por el Estado en el siglo XIX, tuvo un papel distinto y muy potente en el discurso político y administrativo. Décadas antes de que Portugal, Italia, el Imperio otomano o las más ricas entre las repúblicas latinoamericanas crearan sus propias burocracias civiles de carácter facultativo y abrieran escuelas para formas ingenieros no militares, España estableció sus cuerpos civiles y fue pionera en convertir en ingenierías nuevos campos, como la agronomía, que no existió como tal ingeniería superior ni siquiera en la admirada Francia hasta 1876 (tras una frustrada experiencia entre 1848 y 1852) y que no se plasmó en este país en un cuerpo de Estado hasta la primera década del siglo xx.

La creación y consolidación temprana en España de las distintas ramas de ingeniería como cuerpos del Estado no fue producto de una voluntad política particular orientada a fomentar el desarrollo o usar las obras públicas para acelerar la convergencia con los países que las élites españolas percibían como faros del «progreso de la civilización». Las elecciones presupuestarias y los resultados reales en kilómetros de caminos y ferrocarriles, en construcción y mejora de los puertos, en creación de estaciones experimentales, en reforestación o exploración y aprovechamiento mineros muestran las políticas públicas no solo no destacaron respecto a las de otros países con niveles parecidos de ingresos, sino que se situaron en niveles parecidos o incluso inferiores. Eso no significa, sin embargo, que los ingenieros y las obras públicas desempeñaran un papel secundario en el desarrollo del Estado español. Al convertirse en un modelo para el reclutamiento de empleados y la administración en el Estado sistema, llegaron a constituir un elemento central en la construcción discursiva del Estado idea en Espańa y, por lo tanto, en la legitimación del Estado nacional periférico, nacido del fin del imperio español.

\section{Bibliografía}

Abrams, P. (1988). Notes on the difficulties of studying the state. Journal of Historical Sociology, 1, 58-89. Disponible en: https://doi.org/10.1111/j.1467-6443.1988.tb00004.x.

Aguilar Civera, I. (2013). El sistema terrestre de comunicaciones: caminos y ferrocarriles. Reflexiones y testimonios. En M. Silva Suárez (2011), Técnica e ingeniería en España. VII. El Ochocientos. De las profundidades a las alturas (pp. 693-738). Zaragoza: Institución Fernando el Católico.

Alder, K. (1999). Engineering the Revolution: Arms and Enlightenment in France, 1763-1815. Princeton: Princeton University Press. 
Ausejo, E. (2007). Quarrels of a Marriage of Convenience: On the History of Mathematics Education for Engineers in Spain. The International Journal for the History of Mathematics Education, 2, 1-13.

Ara Torralba, J. C. (2007). Asombros, euforias y recelos: consideraciones acerca de la percepción del progreso técnico en la literatura del siglo xix. En M. Silva Suárez (ed.). Técnica e ingeniería en España. Vol. 4, El Ochocientos: pensamiento, profesiones y sociedad (pp. 427-465). Zaragoza: Prensas Universitarias de Zaragoza; Instituto Fernando el Católico.

Aznar García, J. V. (2011). La unificación de los pesos y medidas. El sistema métrico-decimal. En M. Silva Suárez (ed.) Técnica e ingeniería en España. VI. El Ochocientos. De los lenguajes al patrimonio (pp. 345-380). Zaragoza: Institución Fernando el Católico.

Bel, G. (2011). Infrastructure and nation building: The regulation and financing of network transportation infrastructures in Spain (1720-2010). Business History, 53, 688-705. Disponible en: https://doi.org/10.1080/00076791.2011.599591.

(2015). España capital, París. ¿Por qué en España se construyen tantas infraestructuras que no se usan?La respuesta económica a un problema político. Barcelona: Destino.

Bourdieu, P. (2012). Sur l'État. Paris: Seuil.

Branco, R. (2009). Cartographic Engineers in Fieldwork. En A. Cardoso de Matos, M. P. Diogo, I. Gouzévitch y A. Grelon (eds.). Jogos de identidade professional: os engenheiros entre a formação e a acção (pp. 269-270). Lisboa: Colibrí.

Brown, J. K., Downey, G. L. y Diogo, M. P. (2009). Engineering Education and History of Technology. Technology and Culture, 50, 737-752. Disponible en: https://oi. org/10.1353/tech.0.0370.

Burgueño, J. (1996). Geografía política de la España constitucional. La división provincial. Madrid: Centro de Estudios Constitucionales.

Capel, H., Sánchez, J. E. y Moncada, O. (1988). De Palas a Minerva. La formación cientifica $y$ la estructura institucional de los ingenieros militares en el siglo XVIII. Madrid: Consejo Superior de Investigaciones Científicas.

Casals Costa, V. (1996). Los ingenieros de montes en la España contemporánea, 1848-1936. Barcelona: Serbal.

Chastagnaret, G. (2000). L'Espagne puissance minière dans l'Europe du XIXe siècle. Madrid: Casa de Velázquez.

Comín, F. (1996). Historia de la Hacienda pública, I. Europa. Barcelona: Crítica.

— y Díaz, D. (2005). Sector público administrativo y estado del bienestar. En A. Carreras y X. Tafunell (dirs.). Estadisticas históricas de España, siglos XIX-XX (pp. 873-966). Madrid: Fundación BBVA.

Cuéllar Villar, D. (2002). Política de obras públicas y políticas liberales. El Ministerio de Fomento (1851-1874). TST, Trasportes, Servicios y Comunicaciones, 2, 42-69.

Fernandes, P. J. (2001). Fomento, Fontismo e Ferrovias. História, 36, 32-39.

Ferri i Ramírez, M. (2015). El ejército de la paz. Los ingenieros de caminos en la instauración del liberalismo en España (1833-1868). Valencia: Universitat de València.

Fornieles Alcáraz, J. (1989). Trayectoria de un intelectual de la Restauración: José Echegaray. Almería: Caja Almería.

Fradera, J. M. (2005). Colonias para después de un Imperio. Barcelona: Bellaterra. 
Frax Rosales, E. (1981). Puertos y comercio de cabotaje en España, 1857-1934. Madrid: Banco de Espańa.

Gómez Mendoza, A. y San Román, E. (2005). Transportes y comunicaciones. En A. Carreras y X. Tafunell (dirs.). Estadísticas históricas de España, siglos XIX-XX (pp. 509-572). Madrid: Fundación BBVA.

Gómez Mendoza, J. (1992). Ciencia y politica de los montes españoles (1848-1936). Madrid: ICONA.

Gouzévitch, I. y Vérin, H. (2005). Sobre la institución y el desarrollo de la ingeniería: una perspectiva europea. En M. Silva Suárez (ed.). Técnica e ingeniería en España, vol. 3, El Siglo de las Luces. De la industria al ámbito agroforestal (pp. 115-163). Zaragoza: Institución Fernando el Católico.

Gouzévitch, I., Cardoso de Matos, A. y Martykánová, D. (2017). La Russie, l’Espagne, le Portugal et l'Empire ottoman: deux siècles de politiques technoscientifiques à l'épreuve des approches comparatistes. En M. Kleiche-Dray (ed.). Les ancrages nationaux de la science mondiale, XVIIIe-XXIe siècles (pp. 239-286). Paris: École d'art et de culture.

Grelon, A. y Gouzévitch, I. (2007). Reflexión sobre el ingeniero europeo en el siglo XIX: retos, problemáticas e historiografías. En M. Silva Suárez (ed.). Técnica e ingeniería en España, vol. 4, El Ochocientos: pensamiento, profesiones y sociedad (pp. 269-321). Zaragoza: Institución Fernando el Católico.

Krohn-Hansen, C. y Nustad, K. (2005). State Formation. Anthropological Perspectives, London: Pluto.

Juliá, S. (2004). Historia de las dos Españas. Madrid: Taurus.

Larkin, B. (2013). The Politics and Poetics of Infrastructure. Annual Review of Anthropology, 42, 327-343. Disponible en: https://doi.org/10.1146/annurev-anthro-092412-155522.

Linz, J. J. (1973). Early State-Building and Late Peripheral Nationalism Against the State: the Case of Spain. En S. N. Eisenstadt y S. Rokkan (eds.). Building States and Nations (pp. 32-112). Beverly Hills: Sage.

Luis, J. P. (2002). L'utopie réactionnaire. Épuration et modernisation de l'État dans l'Espagne de la fin de l'Ancien Régime (1823-1834). Madrid: Éditions de la Casa de Velazquez.

Lusa Monforte, G. (1994). Industrialización y educación: los ingenieros industriales (Barcelona, 1851-1886). En R. Enrich et al. (eds.), Tècnica i Societat en el Món Contemporani (pp. 61-80). Sabadell: Museu d'História de Sabadell.

Macedo, M. C. (2012). Projectar e Construir a Nação: Engenheiros, ciência e território em Portugal no século XIX. Lisboa: Imprensa de Ciências Sociais.

Madrazo, S. (1984). El sistema de transportes en España, 1750-1850. Madrid: Turner.

Malatesta, M. (2006). Professionisti e gentiluomini. Storia delle professioni nell'Europa contemporanea. Torino: Einaudi.

Martykánová, D. (2016). Remover los obstáculos. Los ingenieros de caminos españoles y sus visiones del Estado durante la segunda mitad del siglo xix. Historia y Política, 36, 49-73. Disponible en: https://doi.org/10.18042/hp.36.03.

— (2017). El amor condenado, el amor triunfante. El género en el discurso sobre la ciencia, la religión y la nación en tres obras de Benito Pérez Galdós. Espacio, Tiempo y Forma, 29, 149-179. Disponible en: https://doi.org/10.5944/etfv.29.2017.19196. 
- (2018). La profession, la masculinité et le travail. La représentation sociale des ingénieurs en Espagne pendant la deuxième moitié du XIXe siècle. En A. Derouet y S. Paye (eds.). Les Ingénieurs. La production d'un groupe social (pp. 79-102). Paris: Garnier.

Massa-Esteve, M. R., Roca-Rosell, A. y Puig-Pla, C. (2011). Mixed Mathematics in Engineering Education in Spain: Pedro Lucuce's course at the Barcelona Royal Military Academy of Mathematics in the eighteenth century. Engineering Studies, 3, 233-253. Disponible en: https://doi.org/10.1080/19378629.2011.618188.

Mitchell, B. R. (1975). European Historical Statistics, 1750-1970. London: Palgrave-Macmillan. Disponible en: https://doi.org/10.1007/978-1-349-01088-2.

Mitchell, T. (1999). Society, Economy and the State Effect. En G. Steinmetz (ed.). State/ Culture. State Formation after the Cultural Turn (pp. 76-97). Ithaca, New York: Cornell Press. Disponible en: https://doi.org/10.7591/9781501717789-005.

Muller, J. (1959). Les ingénieurs militaires dans les Pays-Bas espagnols (1500-1715). Revue International d'Histoire Militaire, 20, 467-478.

Muro, J. I., Nadal, F. y Urteaga, L. (1996). Geografía, estadistica y catastro en España, 18561870. Barcelona: Serbal.

Muro, J. I. y Casals, V. (2011). Cartografía e ingeniería. En M. Silva Suárez, M. (2011). Técnica e ingeniería en España. VI. El Ochocientos. De los lenguajes al patrimonio (pp. 121-170). Zaragoza: Institución Fernando el Católico.

Nadal, J. (1975). El fracaso de la revolución industrial en España, 1814-1913. Barcelona: Ariel

Ordóñez Rodríguez, J. (2007). Ingenieros, utopía y progreso en la novela española del Ochocientos. En M. Silva Suárez (ed.). Técnica e ingeniería en España, vol. 4, El ochocientos: pensamiento, profesiones y sociedad (pp. 467-514). Zaragoza: Institución Fernando el Católico.

Ortí, A. (1996). En torno a Costa (populismo agrario y regeneración democrática en la crisis del liberalismo español): en el 150 aniversario del nacimiento de Joaquin Costa. Madrid: Ministerio de Agricultura, Alimentación y Medio Ambiente.

Pan-Montojo, J. (2005). Apostolado, profesión y tecnología. Una historia de los ingenieros agrónomos en España. Torrelodones, Madrid: B\&H.

- (2006). El atraso económico y la regeneración. En J. Pan-Montojo (ed.). Más se perdió en Cuba (pp. 267-340). Madrid: Alianza.

— (2007). Ciudadanos y contribuyentes. En M. Pérez Ledesma (dir.). De súbditos a ciudadanos. Una historia de la ciudadanía en España (pp. 483-520). Madrid: Centro de Estudios Constitucionales.

- (2014). Progreso material, fomento y libertad: la economía en las culturas políticas del periodo isabelino. En M. C. Romeo y M. Sierra (eds.). La España liberal, 1833-1874 (pp. 51-88). Zaragoza: Prensas Universitarias de Zaragoza.

Peyrou, F. (2008). Tribunos del pueblo. Demócratas y republicanos durante el reinado de Isabel II. Madrid: Centro de Estudios Políticos y Constitucionales.

Pro, J. (1994). Fraude, statistique et pouvoir dans l'Espagne libérale (1840-1868). Revue d'histoire moderne et contemporaine, 41(2), 253-268. Disponible en: https://doi. org/10.3406/rhmc.1994.1719.

— (2017). El modelo francés en la construcción del Estado español: el momento moderado. Revista de Estudios Politicos, 175, 299-329. Disponible en: https://doi.org/10.18042/cepc/ rep. 175.10 . 
(2019). La construcción del Estado en España. Una historia del siglo XIX. Madrid: Alianza. Rosado Pacheco, S. (2000). El Estado administrativo en la España del siglo XIX: liberalismo e intervencionismo: (notas históricas a propósito del fomento, la expropiación y la contratación administrativa, 1836-1869). Madrid: Centro de Estudios Políticos y Constitucionales.

Rosanvallon, P. (1990). L'État en France. De 1789 à nos jours. Paris: Seuil.

Schaub, J. F. (2003). La France espagnole. Les racines historiques de l'absolutisme français. Paris: Seuil. Disponible en: https://doi.org/10.14375/NP.9782020407694.

Scott, J. (1999). Seeing with the State eyes. How Certain Schemes to Improve the Human Condition Have Failed. New Haven y Londres: Yale University Press.

Silva Suárez, M. (1999). Uniformes, símbolos y emblemas de la ingeniería civil española (18351975). Zaragoza: Institución Fernando el Católico.

- (ed.) (2007). Técnica e Ingeniería en España, vol. 5, El ochocientos, Profesiones e instituciones civiles. Zaragoza: Institución 'Fernando el Católico.

— y Lusa Monforte, G. (2007). Cuerpos facultativos del Estado versus profesión liberal. En M. Silva Suárez (ed.). Técnica e ingeniería en España, vol. 4, El Ochocientos: pensamiento, profesiones y sociedad (pp. 323-386). Zaragoza: Institución Fernando el Católico.

Sommer, D. (2009). Ficciones fundacionales: las novelas nacionales de América Latina. México: Fondo de Cultura Económica.

Veiga, X.R. (2017). Poderes locales y construcción del Estado en el siglo xIx (1808-1874). Ayer, 108(4), 285-302. 